\title{
Evaluation of the Exposure to Environmental Pollutants Emanating from National Industrial Complexes
}

\author{
Sanghyuk Bae', Jonghyuk Choi', Geunbae Kim², Sanghwan Song', Mina Ha', Hojang Kwon ${ }^{1}$ \\ 'Department of Preventive Medicine, College of Medicine, Dankook University, Cheonan, Chungnam, Republic of Korea; ${ }^{2}$ Environmental Health Research \\ Division, National Institute of Environmental Research, Incheon, Republic of Korea
}

\begin{abstract}
The industrial complexes built during the course of economic development in South Korea played a pivotal role in the country's rapid economic growth. However, this growth was accompanied by health problems due to the pollutants released from the industrial complexes inevitably located near residential areas, given the limited land area available in South Korea. This study was conducted to evaluate the exposure to each pollutant emanating from industrial complexes for residents living in nearby areas, and to determine the substances requiring priority attention in future surveys. Pollutants were comprehensively categorized according to their emission and exposure levels based on data previously collected from the study areas. The emission, ambient concentration, and biomarker concentration levels of major pollutants emitted from eight national industrial complexes (Ulsan, Pohang, Gwangyang, Yeosu, Chungju, Daesan, Sihwa, and Banwol) were determined and tabulated. Each of the values was compared with the national/local average values, reference values, or control area concentrations depending on availability. Substances with completed exposure pathways and with high values for emissions, ambient concentrations, and biomarker concentrations were considered the substances posing exposure risks to the residents living near the corresponding industrial complex. The substances requiring continuous monitoring or supplementary exposure investigation were also categorized and presented. Lead and benzene had higher values for emissions, ambient concentrations, and biomarker concentrations in the Ulsan Industrial Complex area; thus, they were most likely to pose exposure risks to residents living in the area's neighborhoods. In other areas, styrene, xylene, cadmium, nitrogen oxide, trichloroethylene, nickel, manganese, and chromium required continuous monitoring, and arsenic, nickel, manganese, and chromium required biomarker measurements. In conclusion, the substances identified and categorized in this study need to be given appropriate attention in future surveys on exposure risks and health effects related to industrial complexes.
\end{abstract}

Keywords: Industrial complex, Exposure assessment, Environmental pollutants, Exposure monitoring

\section{INTRODUCTION}

The Ulsan Industrial District was constructed in the 1960s and the 1970s witnessed a series of industrial complexes (ICs) constructed in cities such as Ulsan, Onsan, Yeocheon, Gwangyang, Pohang, Changwon, and Geoje under the government's policy of promoting heavy industries. As of 2015, a total of 1,124 ICs, 41 of them being national ICs, were in operation

Received: November 30, 2017 Accepted: February 26, 2018

Corresponding author: Hojang Kwon

Department of Preventive Medicine, College of Medicine, Dankook University,

Dandae-ro, Dongnam-gu, Cheonan-si, Chungnam, 31116 Republic of Korea

E-mail: hojang@dankook.ac.kr

Funding source: This study was funded by the National Institute of Environmental Research within the framework of the Project "Comprehensive Evaluation on the Result of four years (2012-2015) Monitoring of Exposure to Environmental Pollutants and Health Effects among Residents Living near Industrial Complex."

This article is available from: $h t t p: / / e-e h t . o r g /$ across the country [1]. ICs have played a pivotal role throughout the course of economic growth in South Korea. However, the accompanying environmental pollution has posed serious problems to the surrounding areas. The situation is aggravated by the fact that most of the ICs are located within cities, and nearby residents are exposed to various health hazards including air/water pollutants, fugitive dust, odors, noise, and psychological stressors.

The "Onsan Case" is a typical example of IC-associated environmental pollution. When the Onsan National IC was constructed in the late 1970s, factories were located in residential areas because an emigration plan had not yet been put in place. The hazardous waste discharged from twelve heavy chemical factories polluted the water and air, resulting in crop damage. Residents suffered from skin, musculoskeletal, and respiratory diseases, which were collectively named "Onsan Disease," and had to be evacuated from the contaminated ar- 
eas [2]. This event was followed by unabated complaints about serious environmental pollution by the residents living in the neighborhoods of Yeocheon, Pohang, and Gwangyang ICs, and a compelling need arose to systematically investigate the health risks caused by ICs.

From that time onwards, the Ministry of the Environment has been monitoring environmental pollutants and health effects in the areas surrounding the national ICs. The "Monitoring Project for Exposure to Environmental Pollutants and Health Effects among Residents Living near Industrial Complexes" (hereinafter, "IC Monitoring Project") launched in 2003 is one of the Ministry's major monitoring measure. This project aims to measure the level of exposure to environmental pollutants and the health status of both residents living near the national ICs and residents of the neighboring communities. Phase I of the project was implemented from 2003 to 2010 as a cohort study, and Phase II (2012-2015) was implemented as a crosssectional study [3]. In addition to the IC Monitoring Project, the Ministry of the Environment measured emissions and ambient concentrations of various pollutants, and also evaluated environmental hazards in the IC areas [4-8].

Environmental monitoring in the IC areas is an important process to measure the damage caused by the related pollutants, to provide basic data for pollution prevention and restoration, and to provide source data in the event of legal disputes $[9,10]$. The process of investigating whether the pollutants emitted from an IC caused a particular health problem is not the same as that of investigating a particular pollutant's health effects. In the former case, the focus is on the exposure to a specific substance; however, since that exposure is already known to cause a certain disorder in most cases, the purpose of the investigation is not to determine whether the targeted substance has adverse health effects, but to determine whether the exposure to that substance has taken place [11]. This can be achieved by comprehensive monitoring of the exposure pathway from emission to the receptor. This study was conducted to collect and analyze the pollutant data comprehensively collected from eight IC areas including Ulsan, Pohang, Gwangyang, Yeosu, Chungju, Daesan, Sihwa, and Banwol, in order to identify the exposure pathways of the pollutants in these areas, and to determine from the results the substances that should be given priority attention in the future.

\section{METHODS}

By extracting data from the report on Phase II of the IC Monitoring Project conducted between 2012 and 2015 [3], we determined the main production lines of each IC and identified the pollutants likely to be released from them. We then tabulated the emissions, ambient concentrations, and biomarker concentrations of the identified pollutants. The extent of exposure in the neighboring areas of the IC was determined by comparing each measured value of the exposure area with that of the control area, if there was a designated control area. The national average or reference value was used for comparison in the absence of a control area. The control areas designated in Phase II of the IC Monitoring Project were chosen as the control areas for this study, which took into account topographical and meteorological factors, as well as distance from the IC [3]. Some areas selected during the course of data collection were also used as control areas.

The self-governing communities where the exposure areas and their respective control areas were located were as follows: Ulsan-si nam-gu and Ulju-gun (Ulsan); Ansan-si and Siheung-si (Sihwa/Banwol); Chungju-si (Chunju); Seosan-si (Daesan); Pohang-si (Pohang); Yeosu-si, Gwangyang-si, and Hadong-gun (Gwangyang Bay area). We tabulated the basic characteristics of the residents of these self-governing communities. The percentage of women and that of the individuals over the age of 65 were estimated using the resident register data provided by Statistics Korea [12], and the remaining parameters were obtained from the questionnaire data collected during the course of Phase II of the IC Monitoring Project [3].

Data on the chemicals released to the environment were obtained from the 2001-2014 data provided by the Pollutant Release and Transfer Registers [13], and the data on the pollutants released to the environment were obtained from the 1999-2013 data provided by the National Air Pollutants Emission Service [14]. The mean value of each air pollutant was calculated from the data collected in 229 self-governing communities without processing the missing data, and the mean value of each chemical released to the environment was calculated from the data obtained from 104 self-governing communities without processing the missing data. The national average emission of each substance (chemical or pollutant) was calculated on an annual basis. The emissions in an IC area were calculated as the annual average of the corresponding self-governing community, and the overall emissions level of each IC was expressed as the percentage of the emissions from the IC compared to the national level.

For the analysis of ambient pollutants used to determine whether the IC areas have higher pollutant values compared with non-IC areas, we collected and analyzed the data collected while implementing the Air Pollution Measuring Network Operation Plan (2011-2015), used the data presented in the 2013-2015 annual air quality reports released by Air Korea 
[15], and used the environmental monitoring data presented in the five reports on hazardous ambient pollutants detected in five ICs (Daesan, Sihwa/Banwol, Ulsan, Pohang, and Gwangyang Bay area) prepared by the National Institute of Environmental Research [4-8].

For biomarker analysis, we used the integrated database from Phase II of the IC Monitoring Project [3] and compared the geometric means of the biomarkers collected from the residents of the exposure and control areas who participated in Phase II of the IC Monitoring Project. The geometric mean was used because the biomarkers showed right-skewed distribution instead of normal distribution. Differences between the two geometric mean values were tested using the Wilcoxon rank-sum test.

Substances showing higher values at all three parts of the exposure pathway, i.e., emissions, ambient concentrations, and biomarker concentrations, were considered the substances having adverse health effects on the residents of the corresponding IC area. Those showing higher values at two of the three parts of the exposure pathway were classified as substances requiring continuous monitoring, and those showing equal or lower values at all parts of the exposure pathway were classified as substances requiring supplementary exposure investigation.

\section{RESULTS}

Table 1 outlines the basic demographic and health-related characteristics of the residents of the study areas. Differences between the exposure and control areas were observed in the following parameters: percentage of women, percentage of individuals aged $(\geq 65)$, income level, and health-related behavior.

Table 2 presents the industrial sectors found in the study areas, and the pollutants released from each industry. Typical pollutants released were heavy metals, volatile organic compounds (VOCs), carbonyl compounds, polycyclic aromatic hydrocarbons, and particulate matter.

The data classified by exposure pathway were collected and compared with the national average, reference value, or control area concentration levels; these results are outlined and presented in the supplementary material (Table S1-S5). The values higher than the national average, reference value, or control area concentration levels were extracted and presented in Table 3. The national average was used as the basis for comparison to determine the substances with higher emissions, and the reference value or control area concentration level was used as the basis for comparison for ambient and

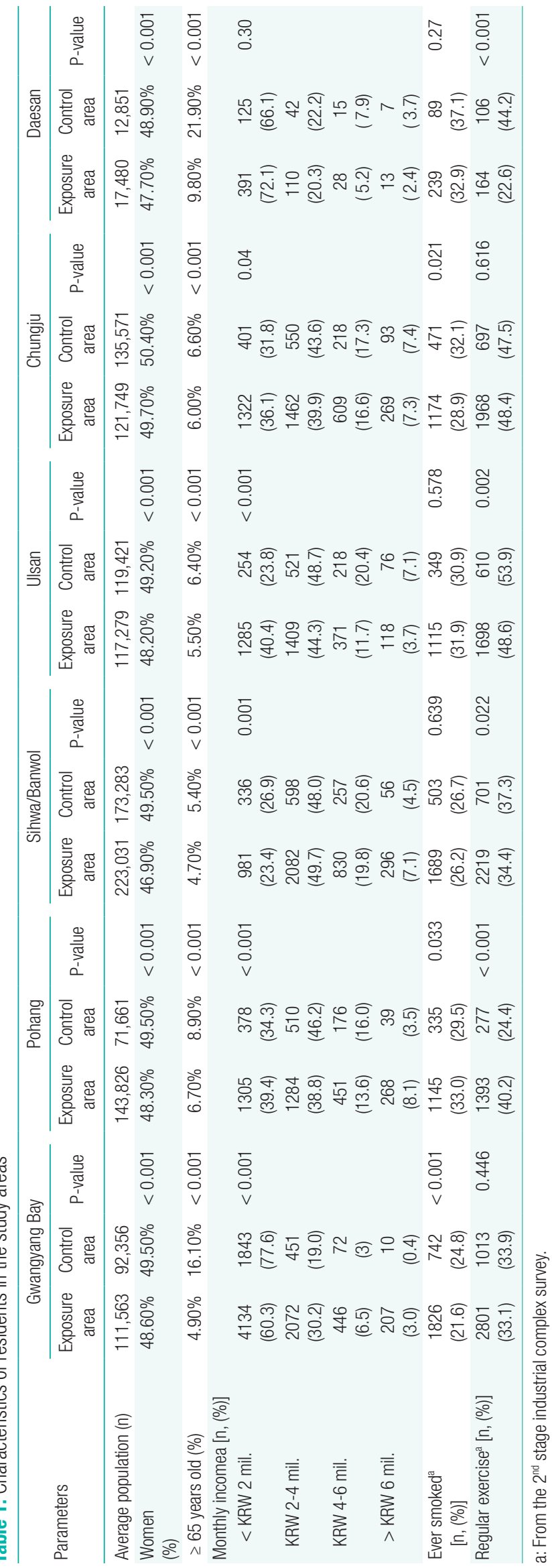


Table 2. Major pollutants and their sources in each area

\begin{tabular}{cccccc}
\hline Parameter & Ulsan & Sihwa/Banwol & Pohang & Gangyang Bay & Chungju/Daesan \\
\hline Pollutants & Heavy metals & Heavy metals & Heavy metals & Heavy metals & Heavy metals \\
& VOCs & VOCs & VOCs & VOCs & VOCs \\
& Carbonyl compounds & PAHs & PAHs & PAHs & PAHs \\
& PAHs & Particulate matter & Particulate matter & Particulate matter & Particulate matter \\
Sources & Particulate matter & Phthalates & & & Textile industries \\
& Petrochemical industries & Industries using VOCs & Steel mills & Steel mills and related industries & Electronics and electric industries \\
& Non-ferrous metal smeltery & Incinerators & Iron industries & Petrochemical industries & Food industries \\
& & & & & Petrochemical industries \\
& & & & & Ceramic ware industries \\
& & & & &
\end{tabular}

VOCs: volatile organic carbons, PAHs: polycyclic aromatic hydrocarbons.

Table 3. Pollutants with higher concentration in the exposure areas

\begin{tabular}{|c|c|c|c|c|c|c|c|}
\hline Categories & & Ulsan & Sihwa/Banwol & Chungju & Daesan & Gwangyang Bay & Pohang \\
\hline $\begin{array}{l}\text { Pollutant } \\
\text { emissions }\end{array}$ & $\begin{array}{c}\text { Higher than national } \\
\text { average }\end{array}$ & $\begin{array}{l}\mathrm{CO}, \mathrm{NH}_{3}, \mathrm{NO}_{x}, \mathrm{PM}_{10}, \\
\mathrm{PM}_{2.5}, \mathrm{SO}_{x}, \mathrm{TSP}, \\
\mathrm{Pb}, \mathrm{As}, \mathrm{Cd}, \mathrm{Mn}, \\
\text { Benzene, Ethyl- } \\
\text { benzene, Xylene, } \\
\text { Styrene, 1,3-Bu- } \\
\text { tadiene, Ethylene } \\
\text { oxide, Vinyl chlo- } \\
\text { ride, Hydrogen } \\
\text { chloride, Phenol, } \\
\text { Formaldehyde, } \\
\text { VOC, Acetalde- } \\
\text { hyde, DBP, DEHP, } \\
\text { Naphthalene }\end{array}$ & $\begin{array}{l}\mathrm{CO}, \mathrm{NO}_{x}, \mathrm{PM}_{2.5}, \mathrm{SO}_{\mathrm{x}} \\
\mathrm{Pb}, \mathrm{Ni}, \mathrm{Cr}, \mathrm{VOC}, \\
\text { Trichloroethylene, } \\
\text { Hydrogen chlo- } \\
\text { ride, Phe nol, } \\
\text { Formaldehyde }\end{array}$ & CO, BBP, DEHP & $\begin{array}{l}\mathrm{CO}, \mathrm{NO}_{\mathrm{x}}, \mathrm{SO}_{\mathrm{x}}, \mathrm{VOC} \\
\text { Styrene }\end{array}$ & $\begin{array}{l}\mathrm{CO}, \mathrm{NH}_{3}, \mathrm{NO}_{x}, \mathrm{PM}_{10}, \\
\mathrm{PM}_{2.5}, \mathrm{SO}_{x}, \mathrm{TSP} \\
\text { VOC, Ni, Mn, Cr, } \\
\text { 1,3-Butadiene, } \\
\text { Benzene, Ethylene } \\
\text { oxide, Styrene, } \\
\text { Phenol, Vinyl } \\
\text { chloride, Hydro- } \\
\text { gen chloride }\end{array}$ & $\begin{array}{l}\mathrm{CO}, \mathrm{NO}_{x}, \mathrm{PM}_{10}, \mathrm{PM}_{2.5} \\
\mathrm{SO}_{x}, \mathrm{TSP}, \mathrm{VOC}, \mathrm{Ni} \text {, } \\
\mathrm{Mn}, \mathrm{Cr}, \text { Naphtha- } \\
\text { Iene, Hydrogen } \\
\text { chloride, Phenol }\end{array}$ \\
\hline \multirow[t]{2}{*}{$\begin{array}{l}\text { Ambient } \\
\text { pollutants }\end{array}$} & $\begin{array}{l}\text { Exceed national } \\
\text { guideline or } \\
\text { international } \\
\text { reference value } \\
\text { (monitoring stations) }\end{array}$ & As, Benzene & $\mathrm{NO}_{2}, \mathrm{PM}_{10}$ & $\mathrm{PM}_{10}$ & & & $\mathrm{Mn}$ \\
\hline & $\begin{array}{l}\text { Exceed national } \\
\text { guideline or } \\
\text { international } \\
\text { reference value } \\
\text { (HAPs reports) }\end{array}$ & $\mathrm{Pb}, \mathrm{Ni}, \mathrm{As}$, Benzene & & & & $\mathrm{Ni}, \mathrm{As}$ & $\mathrm{Ni}, \mathrm{As}, \mathrm{Mn}$ \\
\hline \multirow[t]{2}{*}{ Biomarker } & $\begin{array}{l}\text { Exceed national } \\
\text { average }^{\mathrm{a}}\end{array}$ & $\begin{array}{l}\mathrm{Pb}, \mathrm{Hg}, \mathrm{Cd}, \mathrm{HA} \text {, } \\
\text { MHA }\end{array}$ & $\begin{array}{l}\text { Cd, HA, MA, PGA, } \\
\text { MHA }\end{array}$ & & $\mathrm{HA}, \mathrm{MA}$ & $\begin{array}{l}\text { HA, MA, MHA, Cd, } \\
\text { MBzP, MEOHP, } \\
\text { MEHHP, MECPP, } \\
\text { 2-naphthol }\end{array}$ & $\begin{array}{l}\text { HA, MA, PGA, Hg, } \\
\text { Cd, 2-naphthol }\end{array}$ \\
\hline & $\begin{array}{c}\text { Higher than control } \\
\text { area }\end{array}$ & $\begin{array}{l}\mathrm{Pb}, \mathrm{Hg}, \mathrm{Cd}, \mathrm{PGA}, \\
\text { t,t-MA, O-MHA, } \\
\text { m-MHA, p-MHA, } \\
\text { MA, MEOHP, ME- } \\
\text { HHP, MECPP, } \\
\text { 2-n a ph thol, } \\
\text { 1-OHP, 2-HF,1- } \\
\text { HPH }\end{array}$ & $\begin{array}{l}\mathrm{Pb}, \mathrm{PGA}, \mathrm{MnBP} \\
\text { MBzP, MEOHP, } \\
\text { MEHHP, MECPP }\end{array}$ & $\begin{array}{l}\text { MA, PGA, m-MHA, } \\
\text { MHA, Pb, MBzP, } \\
\text { MECPP }\end{array}$ & $\begin{array}{l}\text { t, t-MA, } 1-0 H P, \\
\text { M BBP, MBzP, } \\
\text { MEOHP, MEHHP, } \\
\text { MECPP }\end{array}$ & $\begin{array}{l}\text { PGA, Cd, MBzP, } \\
\text { 2-naphthol, 2-HF }\end{array}$ & $\begin{array}{l}\text { m-MHA, Pb, 1-OHP, } \\
\text { 1-HPH }\end{array}$ \\
\hline
\end{tabular}

a From the $2^{\text {nd }}$ stage National Environmental Health Survey.

PGA: phenylglyoxylic acid, t,t-MA: t,t-muconic acid, MHA: methylhippuric acid, HA: hippuric acid, MA: mandelic acid, 1-OHP: 1-hydroxypyrene, 2-HF: 2-hydroxyfluorene, 1-HPH: 1-hydroxyphenanthrene, MnBP: monobutyl phthalate, MBzP: monobenzyl phthalate, MEOHP: mono-(2-ethyl-5-oxohexyl)phthalate, MEHHP: mono-(2-ethyl-5-hydroxy-hexyl) phthalate, MECPP: mono(2-ethyl-5-carboxypenty))phthalate.

biomarker concentrations. The results were arranged by exposure pathway and presented in Table 4 .

In the Ulsan IC, lead and benzene were found to have higher values in all three parts of the exposure pathway, which al- lowed the assumption that the higher exposure levels of the biomarker test subjects in the exposure area compared with test subjects in the control area was ascribable to the environmental pollutants released from the IC. Styrene, xylene, and 


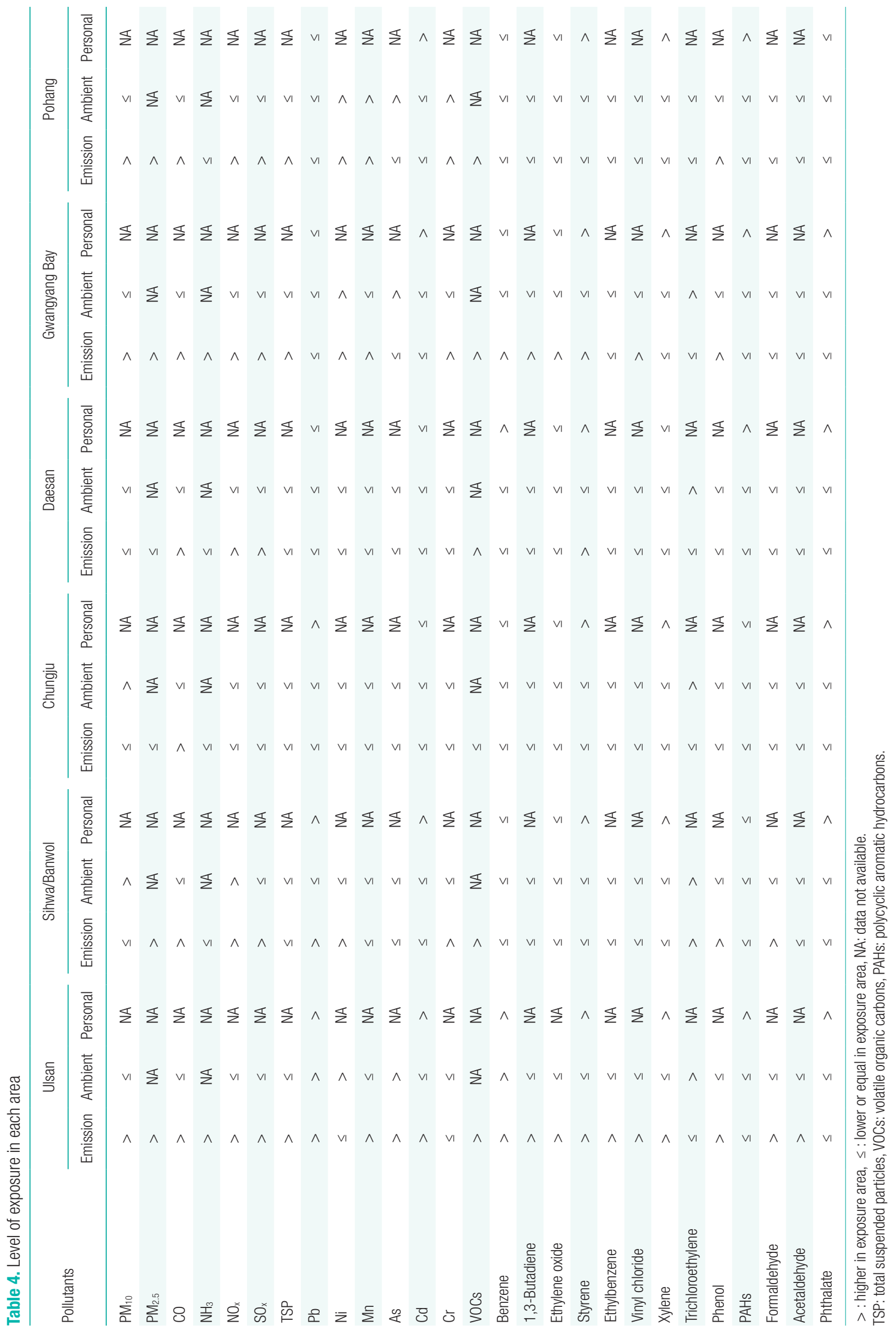


cadmium had higher values for emissions and biomarker concentrations, but not for ambient concentrations, and thus their exposure pathways require continuous monitoring. Arsenic had higher values for emissions and ambient concentrations compared with the national average and the reference value, respectively; however, biomarker measurements were not made, so a supplementary exposure investigation is required.

In the Sihwa/Banwol IC, lead had a higher emissions value than the national average and had a higher value than the reference value for biomarker concentrations, but not in ambient concentrations; thus, its exposure pathway requires continuous monitoring. Nitrogen oxide had higher emissions values than the national average and had a higher value than the reference value for ambient concentrations, but it requires supplementary exposure investigation because no biomarker measurements were made to determine the human exposure to the substance itself or to its metabolites. As for trichloroethylene, which is a carcinogen, it could not be determined whether its values were in excess of the reference value for lack of safety standards; however, there were potential IC-related adverse health effects, and thus the chemical requires supplementary exposure investigation given its higher emissions value compared with the national average, and higher ambient concentrations compared with the control area.

In the Daesan IC, styrene had higher emissions than the national average and had a higher value than the reference value for biomarker concentrations, but not for ambient concentrations, and thus its exposure pathway requires continuous monitoring.

In the Gwangyang Bay area IC, styrene had higher emissions than the national average and had a higher value than the reference value for biomarker concentrations, but not for ambient concentrations, and thus its exposure pathway requires continuous monitoring. Nickel had higher emissions than the national average and had higher ambient concentrations compared with the reference value; however, since no biomarker measurements were made, a supplementary exposure investigation is required.

In the Pohang IC, nickel, manganese, and chromium had higher emissions than their respective national averages and had higher ambient concentrations compared with their respective reference values; thus, they require continuous monitoring, and a supplementary exposure investigation is also required because no biomarker measurements were made.

\section{DISCUSSION}

In this study, we investigated the concentrations of environ- mental pollutants in three parts of their respective exposure pathways from source to receptor population in eight (ICs) in South Korea. Each value was compared with the national average or the reference value, and for each IC the related substances were placed in three categories: (i) substances with high concentrations in all three parts of the exposure pathway, and thus suggesting exposure to the pollutants emanating from the corresponding IC; (ii) substances with one of the ambient and biomarker concentrations not higher than the reference value, and thus requiring continuous monitoring; (iii) substances with unmeasured values, and thus requiring supplementary exposure investigation. Substances with completed exposure pathways have the following implications: (i) the corresponding areas emit more hazardous materials than other areas; (ii) these hazardous materials transfer through environmental media; (iii) high biomarker concentrations in nearby residents means that the residents are exposed to the hazardous materials. Taken together, the residents of affected areas have higher potential for adverse health effects than those in other areas.

Tracking exposure pathways is one of the methods for determining the impacts of the environmental pollutants emanating from an IC on the health status of the residents living in its neighborhoods. However, this type of analysis has been rarely performed. For example, a study reporting the association between the Sihwa/Banwol IC and increased blood lead levels and reduced pulmonary function in nearby residents [16], and another study reporting the association between various IC areas and elevated urine cadmium concentrations and decreased bone mineral density in nearby residents [17] performed biomarker-based exposure assessments without verifying the causal relationship between the high biomarker concentrations and the pollutants released from the corresponding IC. A survey was conducted among the residents of the exposure areas and control areas as part of the IC Monitoring Project, but it was impossible to confirm whether the inter-area difference was ascribable to the IC using only the questionnaire-based cross-sectional correlation [3]. Survey methodology based on the comparison of parts of the exposure pathway from the emission source to the receptor population, as used in this study, can compensate for the limitations of the previous studies in verifying the contribution of an IC.

In this study, the exposure areas around the Ulsan IC showed high lead emissions, ambient concentrations, and biomarker concentrations, allowing the assumption that nearby residents are exposed to pollutants emanating from the IC. Lead is a heavy metal, and a blood lead level of $5 \mu \mathrm{g} / \mathrm{dL}$ or more is known to cause health problems in adults, such as hyperten- 
sion, kidney dysfunction, obstetric complications such as spontaneous abortion and low birth weight, neurological and cognitive disorders, anemia, and cancer [18]. Young children in particular can suffer from various health effects, such as neurodevelopmental disorders, at lower blood lead levels [19]. The mean biomarker concentration of lead in the Ulsan IC exposure areas was $2.27 \mu \mathrm{g} / \mathrm{dL}$; although it was under the $5 \mu \mathrm{g} / \mathrm{dL}$ mark, it was still significantly higher than the national average $(1.94 \mu \mathrm{g} / \mathrm{dL})$ and the control area average $(1.96 \mu \mathrm{g} / \mathrm{dL})$ (Table S5), suggesting potentially increased exposure-related health effects compared with the national or local levels. Therefore, there is a need to conduct an in-depth investigation into the lead exposure-related health effects in the Ulsan IC area.

Benzene is a VOC known to be carcinogenic to humans. Chronic exposure to benzene can cause hematopoietic cancers or anemia. Acute exposure is associated with symptoms such as drowsiness, dizziness, tachycardia, headache, tremor, confusion, unconsciousness, and even death at high concentrations [20]. Detection of acute exposure was beyond the scope of this study; high exposure to benzene in all parts of the exposure pathway from the emission source to the receptor population probably indicates chronic exposure levels. Whereas the exposure area average of urinary $\mathrm{t}, \mathrm{t}$-muconic acid, a biomarker of exposure to benzene, was not higher than the national average, it was significantly higher than the control area average. The higher exposure level in the exposure (IC) areas than in the control (non-IC) areas suggests that the exposure level was influenced by the IC, which was the major source of benzene. Thus, there is a need to investigate whether residents in exposure areas are more vulnerable to health effects than residents in control areas.

The significance of this study lies in overcoming the limitations of previous surveys and research, through which it was impossible to determine the contribution of an IC to high exposure, using the method of concentration comparison at each part of an exposure pathway. This method allowed us to list the substances for each IC area whose exposures were expected to be high under the influence of that IC. However, there were some limitations related to the datasets used in this process, attributable to the collection process itself. The comparison units for the assessment of exposure to a specific source of contamination, such as ICs, are the nearby residents, the nation, self-governing community, and control area. The accuracy of comparison increases in the order of enumeration given the purpose of determining the health effects of an IC. National and regional data are easy to obtain, but are not as reliable for causality determination of the health effects of an IC because of various other regional characteristics. For exam- ple, there are other sources of contamination in most self-governing communities, and the impacts of these other sources of contamination cannot be ruled out even within the self-governing community where an IC is located. Designation of a control area can be used to overcome this drawback. However, its accuracy can vary according to the method used to designate the control area. For example, a simple distance-dependent designation method would be less accurate than an exposure-based designation method based on a diffusion mod$\mathrm{el}$, in which a boundary line is set according to the presence or absence of exposure, and the areas within and beyond the boundary are set as the exposure and control area, respectively [21].

In this study, source emission assessment was performed by tabulating the emissions of the regions hosting the ICs at the self-governing community level, and by comparing each mean value with the national average. This mean value was obtained from the total emissions of the self-governing community, and as such, it did not necessarily reflect the emissions from the IC. Moreover, the emission assessment period was longer than the assessment period of other indicators, and some measurement periods did not coincide, which was a limitation for the direct link between the ambient and biomarker concentrations. The ambient concentrations were measured using two data types, namely station-based continuous measurement data and ad hoc measurement data from specific measurement programs. The station-based measurements were temporally representative, but did not reflect spatial variations, and the ad hoc measurement data did not have temporal representativeness. Additionally, due to the temporal deviation from the biomarker collections, the measurement data could not be directly related to the actual exposure of the receptor population.

Individual-level exposure assessments should be performed for some of the substances extracted in this study; this can be executed using biomarkers and diffusion or air pollution models [21,22]. Related methodologies should be developed for use in future surveys.

In this study, lead and benzene were found to have high concentrations in all parts of their exposure pathways in the neighborhoods of the Ulsan IC. This result suggests the necessity to conduct an in-depth investigation into the health effects of these substances. Additionally, substances requiring continuous monitoring or supplementary exposure investigation were presented for all study areas. For future exposure monitoring and assessment of health effects in areas near ICs, it is necessary to establish a survey system reflecting the results of this study. 


\section{ACKNOWLEDGEMENTS}

There are no conflicts of interest related to this article. Our sincere thanks are due to Hyung-Ryul Lim, Hyunju Joo, HeeSun Yang, Hee-Chan Kim, Yo-Sup Joo, Ji-Hyun Shin, Seol Han, and Jin-Yong Kim for their help with data processing.

\section{REFERENCES}

1. Korea Industrial Complex Corporation. Annal of Korean Industrial Complexes. 2016 (Korean).

2. Institute of Korea Pollution Problem.Dissecting Onsan Disease: Report on Onsan Pollution. New Family; 1985, p. 115-124. (Korean)

3. National Institute of Environmental Research. Comprehensive Evaluation on the Result of Four Years (2012 2015) Monitoring of Exposure to Environmental Pollutants and Health Effects among Residents Living near Industrial Complex; 2016 (Korean).

4. National Institute of Environmental Research. Survey of Hazardous Air Pollutants in Ulsan Area. Incheon; 2010 (Korean).

5. National Insitute of Environmental Research. Survey of Hazardous Air Pollutants in Daesan Area. Incheon; 2012 (Korean).

6. National Insitute of Environmental Research. Survey of Hazardous Air Pollutants in Pohang Area. Incheon; 2013 (Korean).

7. National Insitute of Environmental Research. Survey of Hazardous Air Pollutants in Sihwa and Banwol Areas. Incheon; 2016 (Korean).

8. National Insitute of Environmental Research. Survey of Hazardous Air Pollutants in Gwangyang Bay Area. Incheon; 2017 (Korean).

9. Neuparth T, Moreira SM, Santos MM, Reis-Henriques MA. Review of oil and HNS accidental spills in Europe: Identifying major environmental monitoring gaps and drawing priorities. Mar Pollut Bull 2012; 64(6):1085-1095.

10. Gray WB, Shimshack JP. The Effectiveness of Environmental Monitoring and Enforcement: A Review of the Empirical Evidence. Rev Environ Econ Policy 2011;5(1):3-24.
11. Bae S, Kim HC, Ye B, Choi WJ, Hong YS, Ha M. Causal Inference in Environmental Epidemiology. Envirion Health Toxicol 2017;32: e2017015.

12. Statistics Korea. Korea Statistics Information Service. Available from: http://kosis.kr/index/index.jsp.

13. National Institute of Environmental Research. Pollutant Release and Transfer Registers. Available from: http://ncis.nier.go.kr/triopen/.

14. National Institute of Environmental Research. National Air Pollutants Emission Service. Available from: http://airemiss.nier.go.kr/mbshome/ mbs/airemiss/index.do.

15. Korea Environmental Corporation. Air Korea. Available from: https:// www.airkorea.or.kr/index.

16. Pak YS, Oh A, Kho YL, Paek D. Lung function decline and blood lead among residents nearby to industrial complex. Int Arch Occup Environ Health.2012;85(8):951-959.

17. Shin M, Paek D, Yoon C. The relationship between the bone mineral density and urinary cadmium concentration of residents in an industrial complex. Environ Res 2011;111(1):101-109.

18. Gidlow DA. Lead toxicity. Occup Med(Chic Ill).2015;65(5):348-356.

19. Advisory Committee on Childhood Lead Poisoning Prevention of the Centers for Disease Control and Prevention. Low Level Lead Exposure Harms Children: A Renewed Call for Primary Prevention. Available from: https://www.cdc.gov/nceh/lead/acclpp/final_document_ 030712.pdf.

20. Agency for Toxic Substances and Disease Registry. Toxicological Profile for Benzene. Available from: https://www.atsdr.cdc.gov/ToxProfiles/tp3.pdf.

21. Pascal M, Pascal L, Bidondo ML, Cochet A, Sarter H, Stempfelet M, et al. A review of the epidemiological methods used to investigate the health impacts of air pollution around major industrial areas. J Environ Pub Health 2013;2013:737926.

22. Jung SW, Lee K, Cho YS, Choi JH, Yang W, Kang TS, et al. Association by Spatial Interpolation between Ozone Levels and Lung Function of Residents at an Industrial Complex in South Korea. Int J Environ Res Pub Health 2016;13(7):728. 